\title{
The amplitude-frequency measurement in non-destructive testing using the eddy current method
}

\section{Keywords:}

eddy current;

amplitude-frequency measurement;

discontinuities detection

\begin{abstract}
The paper describes a miniaturized device that records changes in voltage amplitude and signal frequency. After applying the measuring probe to the surface of the tested material, the voltage and frequency amplitude changes. In a place free from defects and nonconformities values of voltage amplitude and frequency are taken as reference values, with which the results obtained during further tests are compared. A clear change in the value of any of the parameters indicates a change in the condition of the tested material. Registration of two parameters with different sensitivity for selected factors allows for a more accurate analysis of the condition of the tested material. The miniaturized device can works in manual measurement mode or in automatic mode, it can be used in defectoscopy, structure and thickness measurements.
\end{abstract}

\section{Introduction}

Non-destructive testing is widely used in practice to assess the quality of parts and components at the stage of their production, as well as to control the operation of existing structures. One of the methods of non-destructive testing is the eddy current method (ET - Electromagnetic Testing or ECT - Eddy Current Testing).

Since the 1950s, the role of testing using eddy current method has increased significantly, particularly in the field of material research for the aerospace and nuclear industry [1]. Thanks to the development of electronics, increased computing power of devices and specialized programming solutions, the eddy current method becomes more attractive and the scope of its application expands. The latest solutions concern multi-transducer probes (ECA - Eddy Current Arrays), including probes with coils in the tangential arrangement (TECA - Tangential Eddy Current Array) [2]. More and more companies offer flexible multi-transducer probes that allow the probe to be easily adjusted to the shape of the tested element. Another example of the development of the ET method is the development of a measuring technique using pulsed eddy currents (PEC - Pulsed Eddy Current) [3]. Innovation of this technique consists in improving the sensitivity of the method by replacing the continuous stimulation with a magnetic field to stimulation with a single impulse. During impulsive stimulation, there is no noise, resulting from the continuous occurrence of eddy currents overlapping each other. The improvement of the signal-to-noise ratio allows the material structure to be examined by high-thickness isolation (up to $200 \mathrm{~mm}$ ) [4].

The basic phenomenon used in non-destructive testing by the eddy current method is electromagnetic induction. It consists of generating electricity in a conductive material as a result of changing magnetic field on it. Variable magnetic field occurs due to powering the coil of the measuring probe with alternating current from the generator of the me-

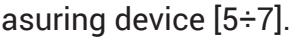

Measurement devices for ET tests are built on the basis of fixed frequency generators or variable frequency generators (generators with freely oscillating resonant circuit).

When using a measuring system with a fixed frequency generator, variables such as voltage amplitude $(U)$ and phase shift angle $(\varphi)$ can be measured. The measurement can be single-parameter ( $U$ or $\varphi$ ) or two-parameter ( $U$ and $\varphi$ ).

For a measuring system with a variable frequency generator, the phase shift angle value is zero $(\varphi=0)$. This type of system enables measurement of the voltage amplitude (U) as well as the frequency ( $f$ ).

The majority of currently used eddy-current defectoscopes use two-parameter measurement. The voltage or impedance components or the amplitude and angle of the phase 
shift of the signal are analyzed. Simpler measuring devices use single-parameter measurement, then the amplitude of the signal is analyzed [5].

Two-parameter measurement, based on the analysis of the voltage amplitude and phase shift angle value, is beneficial due to the possibility of distinguishing discontinuities, determining their occurrence depth, and the ability to detect other factors affecting the measurement signal, such as: change in material thickness, edge effect, lift off. The amplitude and phase evaluation is required if there are many factors affecting the measurement signal during the test. An example is the non-destructive inspection of heat exchanger tubes. In this case, thanks to the use of a two-parameter measurement, it is possible to detect discontinuities, assess their size, determine the location of the discontinuity (inside or outside wall of the tube), and detect changes in the wall thickness of the tube.

\section{Amplitude-frequency measurement in non-destructive testing}

The method of conducting non-destructive tests using the eddy current method described in the paper extends the capabilities of measuring devices, which operate on the basis of a generator with a freely oscillating resonant circuit, by two-parameter measurement: measurement of voltage amplitude and signal frequency ( $U$ and $f$ ).

After applying the measuring probe to the surface of the test material, the voltage and frequency amplitude changes. In a place free from defects and incompatibilities, the determined values of voltage amplitude and frequency are taken as reference values with which the results obtained during further tests are compared. A clear change in the value of any of the parameters indicates a change in the electromagnetic parameters of the tested material. These changes may be caused by changes in hardness, structure change, presence of discontinuities, etc. Places where they occur are considered as non-conformities or defects, depending on the quality assessment criteria.

In the amplitude-frequency measurement method, the main technique of imaging the results is the course of voltage amplitude and frequency over time. It is also possible to separate these two parameters and display them separately by.

- course of the voltage amplitude in time or in regard to the measuring point;

- course of the frequency in time or in regard to the measuring point.

The method can be used in defectoscopy, structureoscopy and thickness measurements.

\section{Control and measurement device - M2 Wirotest}

At the Institute of Precision Mechanics, a miniaturized control and measurement device for non-destructive testing using the eddy current method and the amplitude-frequency measurement was developed - the M2 Wirotest. The block diagram of the device is shown in Figure 1.

M2 Wirotest records changes in frequency and voltage generated by the eddy-current module connected to the measuring probe. The main element that manages the work of the entire device is the microcontroller. The microcontroller's task is to support the analog-digital converter, frequency measurement, as well as processing and sending the data. The converter with the reference voltage is the element that processes the analog signal from the eddy-current module. Separation of the resonant system from the frequency measuring system is made using a conditioning module containing a CMOS amplifier with a low input capacity. Frequency measurement is performed by the method of counting impulses in a given time interval. A replaceable measurement probe is connected to the eddy-current module. The probe's coil is excited from the generator and is part of the resonance circuit. By changing the coil and set of capacitors it is possible to change the operating frequency of the device. The device is connected via an USB adapter with an external device (computer, tablet or smartphone), which is a power source and a processing, displaying and archiving unit of the measurement data.

Figure 2 presents the M2 Wirotest in various configurations: without the measuring head and with the measuring head. The presented head has an absolute contact probe with a ferrite core. The device can be connected with heads of various shapes, dimensions and parameters (frequency, field of view), as well as an adapter allowing to connect a surface probes, encircling coils, internal and profiled/ shape probes compatible with Wirotest 1000 with a coaxial cable. The change of the head is simple and fast, it does not require the operator to reconfigure the device.

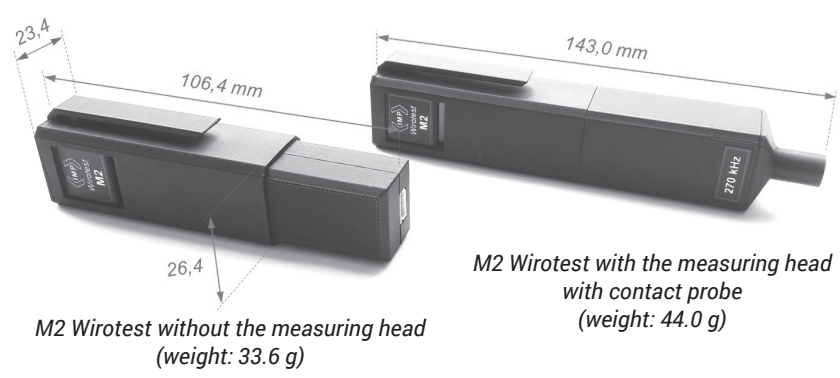

Fig. 2. The Wirotest M2 without head and with measuring head - external dimensions and weight

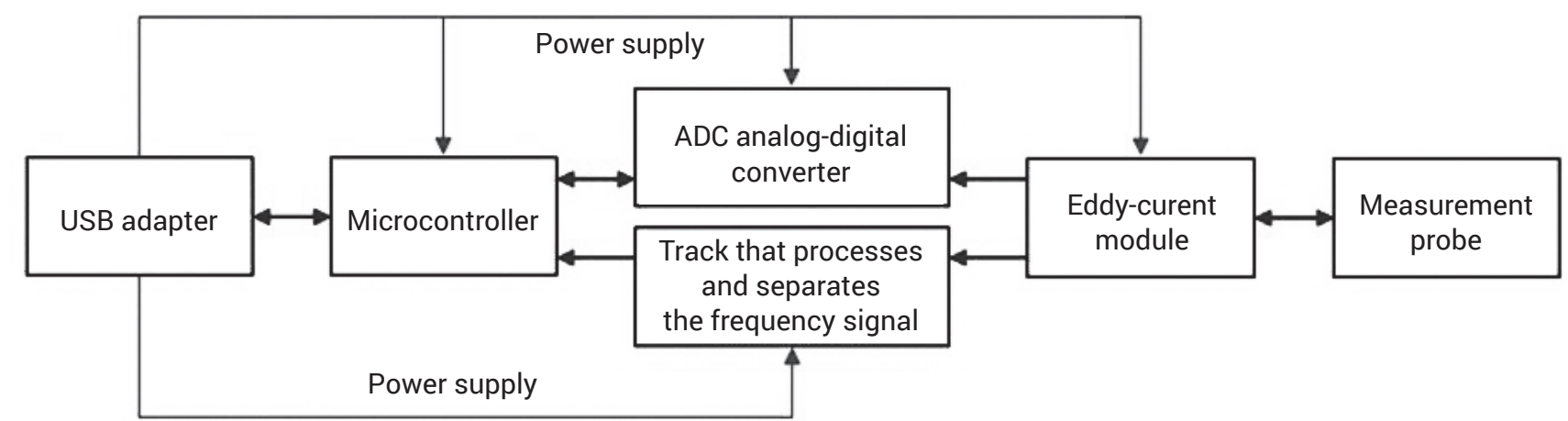

Fig. 1. The Wirotest M2 block scheme 
M2 Wirotest cannot be calibrated by the operator. After connecting a given measuring head, it works with a specified frequency and sensitivity. The reference standards or samples should be used to periodically check the correctness of the device operation. The lack of buttons and knobs eliminates the risk of changing the settings of the measurement parameters in a random manner. The M2 Wirotest is characterized by intuitive operation, it does not require advanced workplace training.

The control and measurement device is characterized by small dimensions and weight (Fig. 2). It can be used for manual operation, e.g. as a portable defectoscope. The ability to work with a tablet or smartphone gives it the character of a mobile and handy device, which is especially important when conducting inspections at a height or in places difficult to access for the operator. The M2 Wirotest can operate in automatic mode, e.g. as one of many sensors on the production line. The limit of the number of sensors is the number of USB ports that the control unit operates for the entire measurement system. The M2 Wirotest has the possibility of modification, after which it can cooperate with external devices using the RS-485 serial bus.

\section{Detection of discontinuities using the M2 Wirotest}

In order to validate the control and measurement device, tests focused on detecting discontinuities (defectoscopy), assessment of surface hardness and differentiation of materials (structureoscopy) and measurement of thickness/ distance were carried out. The test results confirmed the correct operation and the possibility of using the device in the above areas. The paper presents the results of amplitude-frequency measurements in detecting discontinuities.

The measurements were carried out on a steel standard block with four notches $0.5 \mathrm{~mm}$ wide and 1, 4, 7.5 and $10 \mathrm{~mm}$ deep. M2 Wirotest was used for the tests with a measuring head with a working frequency of $278 \mathrm{kHz}$ (in the air). Movement of the measuring device was carried out on the AutoWir-S1 automatic station (Fig. 3) [8]. The measurement took place in a contact manner.

Discontinuity of the material causes a marked increase in the voltage amplitude (Fig. 4) and a decrease in the signal frequency (Fig. 5). Analysis of changes in both parameters allows effective detection of such defects.

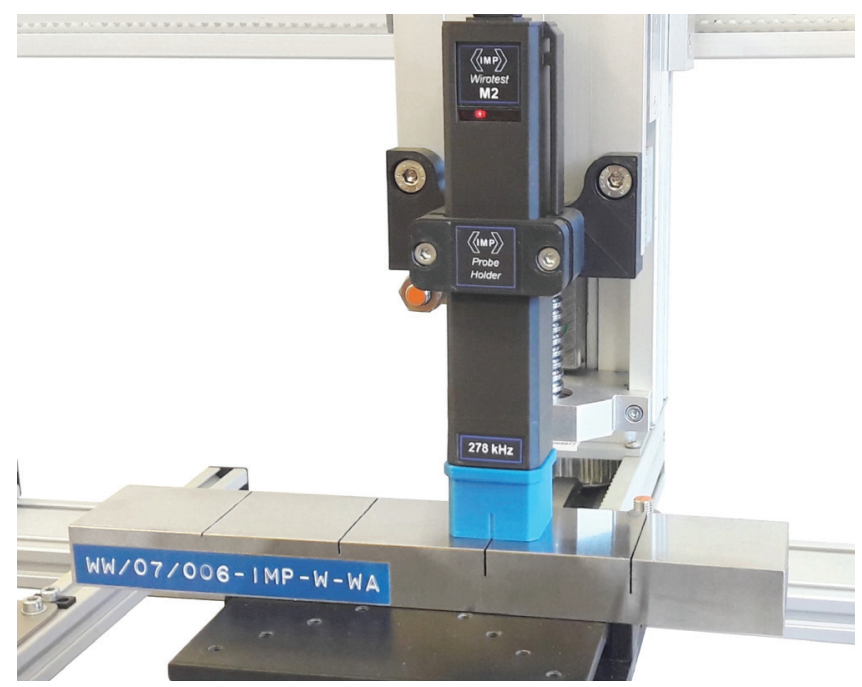

Fig. 3. The Wirotest M2 during test on the reference standard with notches in automatic mode
The discontinuities occurring in the test material influence the shape of the eddy current flow paths. The amplitude of the output signal of the eddy-current converter is an entangled function of the depth, length and width of the discontinuity $[5,6]$. The greater the discontinuity of the material, the higher the amplitude of the signal.

Amplitude analysis allows to distinguish three notches, while the fourth one (the deepest $-10 \mathrm{~mm}$ ) does not cause the voltage amplitude to change so much that it is possible to correctly estimate its size (depth). The height of the signal peak informs about the depth of the notch and it should be referred to the signal level for the homogeneous material surrounding that notch. The obtained graph of changes in the voltage amplitude (Fig. 4) shows that in some cases the determination of this level is difficult.

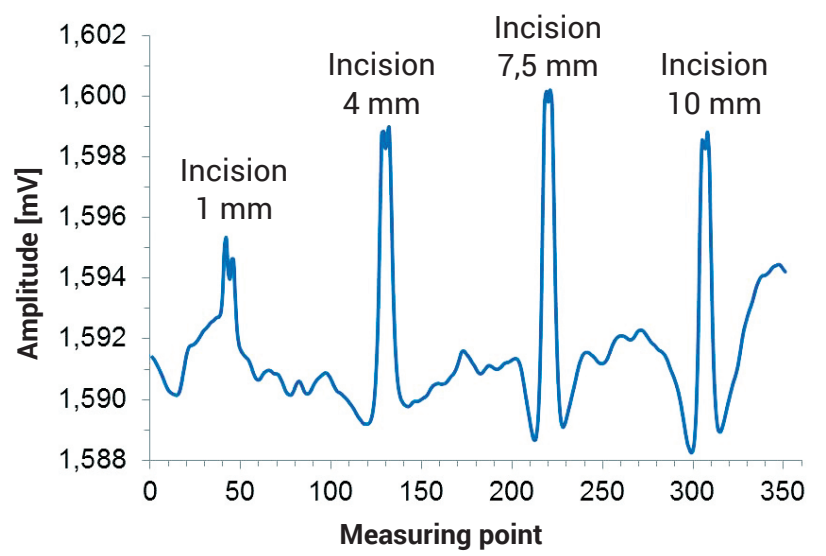

Fig. 4. The voltage amplitude graph for the reference standard with notches

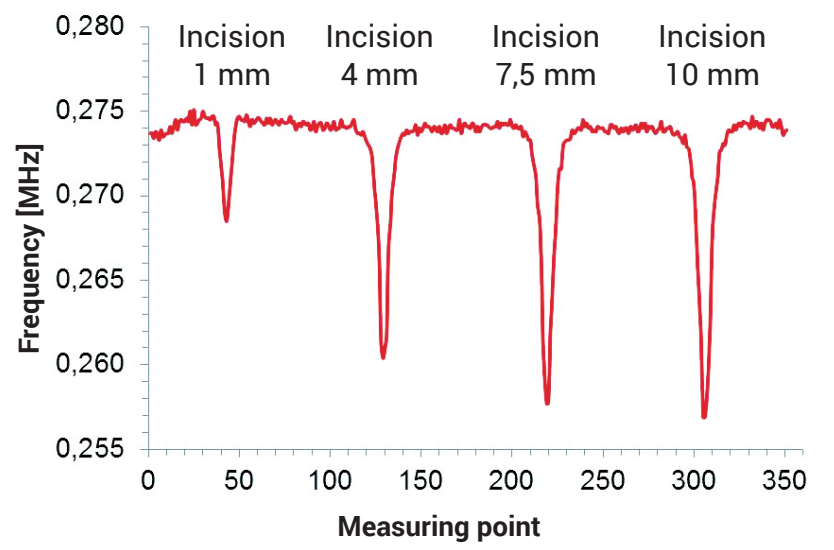

Fig. 5. The signal frequency graph for the reference standard with notches

To assess the size (depth) of discontinuities in the presented case, frequency analysis is more useful (Fig. 5). It allows to evaluate the depth for all notches. The obtained graph of frequency changes in relation to the measurement point is characterized by smaller fluctuations for the areas between the notches and clear peaks for the notches. As a result, the indirect assessment of the depth of the notch is simpler, and the error of this assessment is smaller than in the case of amplitude analysis.

The main imaging of results in the described measurement technique is the course of voltage amplitude and frequency of the signal in time (Fig. 6). The amplitude-frequency analysis allows detection and evaluation of the depth of all notches. 


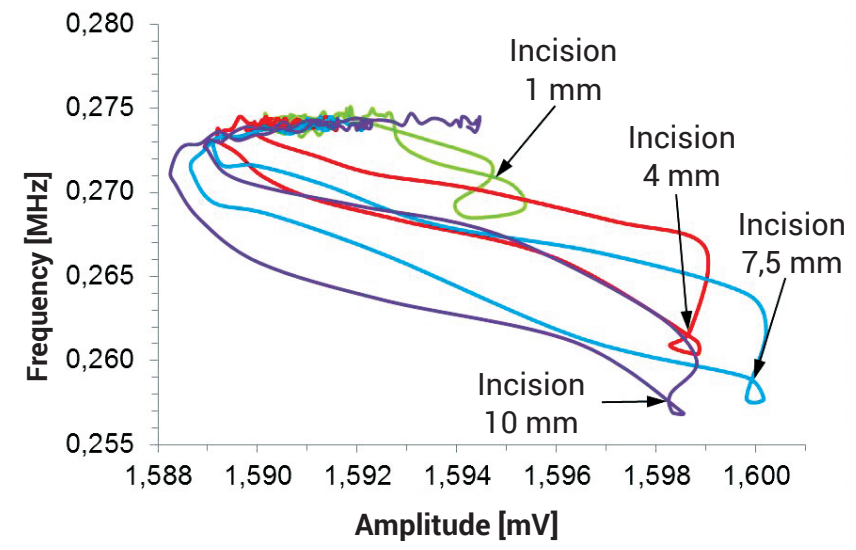

Fig. 6. The frequency and amplitude of the signal for the reference standard with notches
After the measuring probe passes through the notch, a trajectory of double-loop shaped signal changes is created in the graph. Its appearance indicates the presence of a discontinuity in the tested material. The size, shape and location of the loop contains information about the size of the discontinuity. As the depth of notch increases, the size of the upper loop increases, the size of the lower loop decreases and its position decreases.

\section{Summary}

The development and manufacture of a miniaturized measuring device for non-destructive testing using the eddy current method extends the capabilities of the IMP apparatuses with a two-parameter measurement.

The amplitude-frequency measurement allows to collect more data and to more accurately analyze the state of the material under investigation.

The creation of the M2 Wirotest allows the development of solutions related to quality control in the industry based on IMP production equipment and extends the area of their application.

The M2 Wirotest is characterized by small dimensions and weight. It can works as a defectoscope or as a measuring device working on an automatic line. It can be used in defectoscopy, structureoscopy and thickness measurements.

The research and execution of the measurement system was carried out at the Institute of Precision Mechanics as part of the statutory work in 2018 entitled: „Zminiaturyzowany układ pomiarowy do badań nieniszczących metodą prądów wirowych", nr 13.1.01.429.00.

\section{References}

[1] J. Garcia-Martin, J. Gómez-Gil, E. Vázquez-Sánchez, Non-Destructive Techniques Based on Eddy Current Testing, Sensors (2011), no. 11, 2525-2565.

[2] M. Sirois, M. Bouchard, A. Raude, R. Boba, Korozja naprężeniowa - kiedy głębokość wady ma znaczenie, Badania Nieniszczące i Diagnostyka (2017), nr 3, 43-46.

[3] A. Sophian, G. Tian, M. Fan, Pulsed Eddy Current Non-destructive Testing and Evaluation: A Review, Chinese Journal of Mechanical Engineering (2017), nr 30, 500-514

[4] Urząd Dozoru Technicznego, website, www.udt.gov.pl/prady-wirowe-guided-waves (accessed: 06.07.2018).
[5] A. Lewińska-Romicka, Badania materiałów. Metoda prądów wirowych, Biuro Gamma, Warszawa (2007).

[6] A. Lewińska-Romicka, Badania nieniszczące. Podstawy defektoskopii, Wydawnictwa Naukowo-Techniczne, Warszawa (2001).

[7] Norma Europejska PN-EN ISO 15549, Non-destructive testing - Eddy current testing - General principles (2011).

[8] A. Kondej, M. Baranowski, K. Niedźwiedzki, S. Jończyk., A. Szczepański, Automatyczne stanowisko do badań nieniszczących metodą prądów wirowych, Inżynieria Powierzchni (2014), nr 1, 57-62. 